\title{
ANÁLISIS DE LAS NOVEDADES INCORPORADAS AL DELITO DE CORRUPCIÓN EN LAS TRANSACCIONES COMERCIALES INTERNACIONALES POR LA LEY ORGÁNICA 1/2015, DE 30 DE MARZO
}

\author{
Demelsa Benito Sánchez
}

\begin{abstract}
SUMARIO: 1 . INTRODUCCIÓN. 2. TRATAMIENTO DE LA CORRUPCIÓN EN TRANSACCIONES COMERCIALES INTERNACIONALES EN LOS INSTRUMENTOS LEgAles INTERNACIONALES. 2.1. Primera iniciativas: la FCPA y las recomendaciones de la OCDE. 2.2. Convenios internacionales. 2.3. Resumen de las obligaciones impuestas a España en materia de corrupción transnacional. 3. LA INCORPORACIÓN AL CÓDIGO PENAL ESPAÑOL DEL DELITO DE CORRUPCIÓN EN LAS TRANSACCIONES COMERCIALES INTERNACIONALES. 4. EL DELITO DE CORRUPCIÓN EN LAS TRANSACCIONES COMERCIALES INTERNACIONALES EN EL NUEVO ART. 286 TER. 4.1. Cambio de ubicación y bien jurídico. 4.2. La eliminación de la expresión "[funcionarios públicos] extranjeros o de organizaciones internacionales» y las consecuencias concursales. 4.3. La finalidad del soborno: "conseguir o conservar un contrato, negocio o cualquier otra ventaja competitiva». 4.4. La pena. 5. CONCLUSIONES Y PROPUESTAS DE LEGE FERENDA.
\end{abstract}

\section{INTRODUCCIÓN}

La corrupción, entendida tradicionalmente como el abuso del poder público en beneficio privado, ha sido una constante a lo largo de todas las socie- 
dades para obtener decisiones favorables de quien ostenta el poder ${ }^{1}$. Sin embargo, pese a ser un fenómeno tan antiguo como el mismo poder, la comunidad internacional comenzó a preocuparse por él relativamente tarde. Las primeras iniciativas supranacionales vinculantes en materia de corrupción datan de la segunda mitad de los años noventa; y el instrumento internacional más importante en esta materia, la Convención de las Naciones Unidas contra la Corrupción, se adoptó ya en el nuevo milenio.

La razón para esta tardía toma de conciencia parece radicar en el hecho de que no es hasta las últimas décadas del siglo XX, por efecto de la globalización, cuando la corrupción adquiere unas magnitudes desorbitadas, convirtiéndose en planetaria $^{2}$, afectando a regímenes autoritarios y a democracias consolidadas, a países en desarrollo y países industrializados, a organizaciones internacionales y a grandes empresas multinacionales ${ }^{3}$.

Una de las particularidades de esta nueva dimensión de la corrupción es su carácter transnacional, que se plasma en la intervención en el pacto corrupto de personas (físicas o jurídicas) vinculadas a países diferentes. Cuando el pacto implica, por un lado, a un particular de un Estado (persona física o jurídica), y por otro, a un funcionario público de otro Estado o de una organización internacional, se habla de soborno transnacional, corrupción transnacional o corrupción de funcionario público extranjero o internacional. Tradicionalmente, estas conductas quedaron fuera de los códigos penales, preocupados únicamente por la corrupción de los propios funcionarios, es decir, la que afecta al funcionamiento de la Administración Pública del propio país. Sin embargo, desde la década de los setenta, algunos países se empezaron a preocupar de la corrupción que acontecía más allá de sus fronteras, esto es, de la corrupción transnacional; y a partir de la década de los noventa, esa preocupación se plasmó en documentos internacionales vinculantes que

${ }^{1}$ Este trabajo se enmarca en el proyecto de investigación Política criminal ante el reto de la delincuencia transnacional, financiado por el Ministerio de Economía y Competitividad del Gobierno de España (Referencia DER2012-31368), IP: Ana I. PÉREZ CEPEDA; igualmente, en el Equipo de investigación Poder público y empresa en un contexto multinivel y transnacional (UD-R2010) reconocido por el Gobierno Vasco para el período 2013-2015 (IT607-13), IP: Luis I. GORDILlo PÉREZ.

${ }^{2}$ La expresión procede de Nieto García, A., Corrupción en la España democrática, Ariel, Barcelona, 1997, p. 51. En sentido similar habla MoOdY-STUART de la gran corrupción (MoOdy-Stuart, G., La gran corrupción, Siddharta Mehta Ediciones, Madrid, 1994.

3 Sobre las causas de esta nueva corrupción, vid. recientemente LuZÓn CÁNOVAS, A., «Instrumentos para la investigación de la corrupción», Cuadernos Penales José María Lidón, $\mathrm{n}^{\mathrm{o}}$ 11, 2015, pp. 235-238. También Berdugo Gómez dE LA Torre, I., Viejo y nuevo Derecho penal. Principios y desafios del Derecho penal de hoy, Iustel, 2012, pp. 181184; Pérez Cepeda, A. I. y Benito SÁnchez, D., «La política criminal internacional contra la corrupción», Revista Brasileira de Ciências Criminais, nº 89, 2011, pp. 14-19. 
obligan a los Estados a castigar como delito estas conductas, similares a las clásicas conductas de cohecho pero con un componente internacional.

España, al igual que mucho otros Estados, se vio obligada a incorporar una nueva modalidad delictiva a su código penal. Sin embargo, el nuevo tipo penal que se incluyó en el texto punitivo ha adolecido desde el principio de diversas deficiencias, lo que ha llevado al legislador a modificarlo en cuatro ocasiones en un período de quince años. La última de esas modificaciones es la introducida por la recién aprobada Ley Orgánica 1/2015, de 30 de marzo. $\mathrm{Al}$ estudio las modificaciones incorporadas por esta reciente ley, sin duda las más relevantes desde la aparición del delito en el texto punitivo, se dedica este artículo. Para ello, se realiza, en primer lugar, un estudio del tratamiento de estas conductas en los instrumentos legales internacionales. Posteriormente, y partiendo de los compromisos internacionales asumidos por España, se expone cómo fue la incorporación de esas conductas al código penal y las diversas modificaciones sufridas. Seguidamente, se estudian en detalle las últimas modificaciones del texto punitivo en esta materia. Por último, se ofrecen unas conclusiones y propuestas de lefe ferenda.

\section{TRATAMIENTO DE LA CORRUPCIÓN EN TRANSACCIONES COMERCIALES INTERNACIONALES EN LOS INSTRUMENTOS LEGALES INTERNACIONALES}

\subsection{Primera iniciativas: la FCPA y las recomendaciones de la OCDE}

Los primeros instrumentos internacionales vinculantes que abordaron el tema de la corrupción transnacional vieron la luz en la segunda mitad de los años noventa. Anteriormente únicamente existieron algunos textos sin carácter vinculante procedentes de algunas organizaciones internacionales. Sin embargo, el documento pionero en la lucha contra estos comportamientos es una ley nacional de 1977, una ley que tuvo una influencia trascendental en los instrumentos internacionales que se adoptarían con posterioridad. Se trata de la estadounidense Foreign Corrupt Practices Act (Ley de Prácticas Corruptas en el Extranjero. En adelante, $\mathrm{FCPA}^{4}$ ), una ley aprobada después de que la Securities and Exchange Commission (SEC) publicara un demoledor informe indicando que alrededor de 400 empresas del país habían realizado pagos cuestionables en sus transacciones comerciales internacionales susceptibles de ser calificados como corrupción en el extranjero 5 . La ley sancionaba penalmente a ciudadanos y empresas norteamericanas que pagaran so-

${ }^{4}$ United States Code: Title 15 - Commerce and Trade, Section 78 dd-1 y ss.

5 CRITES, D. M., «The Foreign Corrupt Practices Act at Thirty-Five: A Practitioner's Guide», Ohio State Law Journal, vol. 73:5, 2012, p. 1050; DARrough, M. N., «The FCPA 
bornos a funcionarios públicos de terceros Estados para obtener o conservar contratos en la realización de actividades comerciales transnacionales.

La recién aprobada FCPA, precisamente por su carácter innovador, no estuvo exenta de polémica. Desde su nacimiento, la clase empresarial norteamericana manifestó su rechazo hacia la misma argumentando que colocaba a sus empresas en una situación de desventaja respecto a sus competidoras europeas o japonesas en el comercio internacional puesto que sus países de origen no contaban con una legislación similar que prohibiera el pago de sobornos a funcionarios públicos extranjeros ${ }^{6}$. Apoyándose en ese argumento, la clase empresarial norteamericana presionó a su gobierno para que reclamara en los órganos decisorios de organizaciones internacionales un texto internacional vinculante que obligara al resto de países a prohibir la entrega de sobornos a funcionarios públicos extranjeros en operaciones comerciales internacionales, tratando de poner fin así a esa situación desventajosa. Sin embargo, el gobierno de Estados Unidos no tuvo éxito con sus presiones, no consiguiendo nada más que textos de soft law en los años subsiguientes ${ }^{7}$.

La Organización para la Cooperación y el Desarrollo Económico (en adelante, OCDE) publicó por aquel entonces sus Líneas directrices para empresas multinacionales, cuyo principio VI, titulado inicialmente «Lucha contra la corrupción», recomendaba a las empresas no ofrecer ni prometer ni dar pagos ilícitos o ventajas indebidas para obtener o conservar contratos u otras ventajas indebidas ${ }^{8}$. La Cámara de Comercio Internacional, por su parte, publicó sus Reglas de conducta para combatir la extorsión y el soborno, con similares recomendaciones a las hechas por la OCDE'.

and the OECD Convention: Some Lessons from the U.S. Experience», Journal of Business Ethics, no 93, 2010, pp. 257-258.

${ }^{6}$ Huber, B., «La lucha contra la corrupción desde una perspectiva supranacional», Revista Penal, $\mathrm{n}^{\circ}$ 11, 2003, p. 42; KocHI, S., «Diseñando convenciones para combatir la corrupción: la OCDE y la OEA a través de la Teoría de las relaciones internacionales», América Latina Hoy, n 31, 2002, p. 101; NIETO MARTín, A., «La corrupción en el comercio internacional (o de cómo la americanización del Derecho Penal puede tener de vez en cuando algún efecto positivo)», Revista Penal, nº 12, 2003, p. 12.

7 Baughn, C., Bodie, N. L., Buchanan, M. A., Bixby, M. B., «Bribery in International Business Transactions «, Journal of Business Ethics, $\mathrm{n}^{\circ}$ 92, 2010, p. 18.

${ }^{8}$ Las Líneas han sido reformadas en diversas ocasiones desde entonces para adaptarlas a los nuevos instrumentos internacionales contra la corrupción. La última revisión data de 2011. El actual principio VII se titula «Lucha contra la corrupción, las peticiones de soborno y otras formas de extorsión», y en él se sigue recomendando no ofrecer ni prometer ni dar pagos ilícitos para obtener o conservar contratos u otras ventajas ilegítimas, a la vez que se hace hincapié en la necesidad de adoptar programas de cumplimiento para prevenir y detectar casos de soborno.

${ }^{9}$ Las Reglas también han sido reformadas a lo largo de estos años para adaptarlas a los nuevos estándares en materia de corrupción. La última versión es igualmente de 2011. 
Las tensiones este-oeste de los años posteriores siguieron impidiendo la adopción de acuerdos vinculantes en el seno de organizaciones internacionales. Las negociaciones al respecto sólo se retomarían finalizada la Guerra Fría. Sin embargo, las iniciativas más relevantes no partieron de la Organización de Naciones Unidas, como quizá hubiera sido lógico pensar en vista de la adopción por aquellos años de otros instrumentos en materias diversas ${ }^{10}$, sino de la OCDE, una organización con marcado carácter económico.

A comienzos de los noventa, bajo la iniciativa de EE.UU., se creó un grupo de trabajo en el seno de esta organización con el objetivo de luchar contra el soborno en el comercio internacional y diseñar unas condiciones de competencia iguales para todas las empresas participantes en él ${ }^{11}$. Los trabajos culminaron con la adopción de la Recomendación para combatir el cohecho en las transacciones comerciales internacionales, de 27 de mayo de $1994^{12}$. No era más que un texto sin carácter vinculante, pero a partir del cual, los Estados firmantes comenzaron a introducir modificaciones en sus Orde-

Su artículo 1 insta a las empresas a prohibir las prácticas de soborno, extorsión, tráfico de influencias y blanqueo de capitales

${ }^{10}$ Es cierto que la ONU aprobó una serie de documentos en materia de corrupción, pero no fueron más que documentos de soft law que apenas tuvieron influencia en la adopción de los posteriores convenios, al contrario de lo que sucedió con las recomendaciones de la OCDE, que fueron el germen del convenio que se adoptaría posteriormente. Entre los documentos de la ONU de esa época están los siguientes: Resolución de la Asamblea General 50/106, Negocios y desarrollo, de 20 de diciembre de 1995 (A/RES/50/106), en la que se recomendaba al Consejo Económico y Social examinar el proyecto de acuerdo internacional sobre pagos ilícitos; Resolución de la Asamblea General 51/59, Acción contra la corrupción y código internacional de conductas para funcionarios públicos, de 12 de diciembre de 1996 (A/RES/51/59), en la que se adoptaba un código de conducta para funcionarios públicos, en el que se señala que éstos no deberán solicitar o recibir directa ni indirectamente regalos u otros beneficios que puedan influir en el ejercicio de su funciones; Resolución de la Asamblea General 51/191, Declaración de Naciones Unidas contra la corrupción y el soborno en transacciones comerciales internacionales, de 21 de febrero de 1997 (A/RES/51/191), que instaba a los Estados miembros a adoptar medidas efectivas y concretas para luchar contra todas las formas de corrupción, soborno y prácticas ilícitas conexas en las transacciones comerciales internacionales, a tipificar como delito los actos de soborno de funcionarios públicos extranjeros, a prohibir la deducción fiscal de las sumas pagadas como sobornos, a elaborar normas y prácticas contables que aumentasen la transparencia de las transacciones comerciales internacionales, a elaborar códigos de conducta que prohibiesen la corrupción en las transacciones comerciales internacionales, a examinar la necesidad de tipificar como delito el enriquecimiento ilícito de funcionarios públicos, y a prestarse la mayor asistencia mutua y cooperación en la investigación de la corrupción transnacional

${ }^{11}$ VV.AA: Las reglas del juego cambiaron: la lucha contra el soborno y la corrupción, OECD Publications, México, 2000, p. 3.

${ }^{12} \mathrm{C}$ (94) 75 FINAL. 
namientos internos con el objetivo de acabar con los pagos ilícitos en el comercio internacional ${ }^{13}$.

La Recomendación de 1994 contenía un compromiso de revisión, fruto del cual nació la Recomendación revisada sobre el combate del cohecho en las transacciones comerciales internacionales, adoptada el 23 de mayo de $1997^{14}$, a la que se agregaron unos «elementos comunes acordados», elaborados por el grupo de trabajo, que constituirían la base de una convención internacional sobre la penalización del soborno a servidores públicos extranjeros.

\subsection{Convenios internacionales}

El instrumento que marca un antes y un después en la lucha contra la corrupción de funcionarios públicos extranjeros es, sin duda, el convenio que se adoptaría en el marco de la OCDE en 1997. No obstante, no hay que olvidar que un año antes, la Organización de Estados Americanos aprobaba el primer instrumento vinculante supranacional en materia de corrupción: la Convención interamericana contra la corrupción ${ }^{15}$. En ella ya se incluía, entre los delitos que debían castigar los Estados parte, el soborno transnacional (art. VIII). Sin embargo, no dejaba de ser un instrumento limitado a un ámbito geográfico muy concreto, y que adolecía de ciertas de carencias que impedían una eficaz implementación y aplicación por parte de los Estados parte ${ }^{16}$.

La OCDE, por su parte, adoptaba a finales de 1997 el Convenio de lucha contra la corrupción de agentes públicos extranjeros en las transacciones comerciales internacionales $^{17}$ (en adelante, Convenio OCDE). El Convenio exige la tipificación del cohecho activo transnacional, es decir, del cometido

13 CEBAdA Romero, A., «La participación española en las acciones internacionales contra la corrupción», Derecho de los Negocios, no 144, 2002, p. 25; CEREZo Domínguez, A. I., «La adaptación del sistema jurídico-penal español a las propuestas internacionales sobre la corrupción administrativa», Actualidad Penal, no 21, 2001, p. 454; FABIÁN CAPARRÓs, E. A., La corrupción de agente público extranjero e internacional, Tirant lo Blanch, Valencia, 2003, p. 65.

${ }^{14} \mathrm{C}$ (97) 123 FINAL.

15 Entró en vigor desde el 6 de marzo de 1997.

16 Sobre la Convención interamericana contra la corrupción, vid. ampliamente, BARAGLI, N. y RAIGORODSKY, N., Convención interamericana contra la corrupción: implementación de un eficaz instrumento internacional de lucha contra la corrupción, Oficina Anticorrupción, Ministerio de Justicia y Derechos Humanos, Buenos Aires, 2004; MANFRONI, C. A. y WERKSMAN, R., La Convención Interamericana contra la corrupción. Anotada y comentada, $2^{\circ}$ edición, Abeledo-Perrot, Buenos Aires, 2001.

17 El Convenio entró en vigor, de forma general, el 15 de febrero de 1999, y para España, el 3 de marzo de 2000, sin embargo, no fue publicado en el BOE hasta dos años más tarde (BOE $\mathrm{n}^{\circ} 46$ de 22 de febrero de 2002). 
por el particular, olvidándose del cohecho pasivo, como ya lo hiciera la FCPA. Y se centra, al igual que aquélla, en el cohecho en transacciones comerciales internacionales, pues el soborno sólo ha de constituir delito si se entrega para conseguir o conservar un negocio u otra ventaja en la realización de actividades comerciales internacionales.

El objetivo del Convenio OCDE era poner fin a toda una serie de conductas que vulneran la competencia leal en el mercado internacional, bien jurídico de referencia en estos delitos ${ }^{18}$. La ausencia de castigo del cohecho pasivo no tiene que ver con la lesividad de la conducta, pues tan perjudicial es para la competencia leal, la conducta del particular como la conducta del funcionario. Las razones para su no tipificación parecen, más bien, procesales y tienen que ver con la dificultad para perseguir y enjuiciar a funcionarios públicos de otros Estados. Dado que éstos estarán realizando una conducta de cohecho pasivo clásico - castigada con toda seguridad en sus respectivos ordenamientos jurídicos-, será el Estado al que pertenece el funcionario el que debe encargarse de su enjuiciamiento ${ }^{19}$.

El problema se plantea con los funcionarios de organizaciones internacionales, pues éstas no pueden perseguirles penalmente dado que carecen de facultades en este ámbito. La no tipificación del cohecho pasivo de funcionarios de organizaciones internacionales puede llevar, por tanto, como de hecho ha sucedido, a la impunidad de estos sujetos, siendo por tanto, completamente dispar e injusto el tratamiento del particular y el del funcionario en estos casos.

La Organización de Naciones Unidas lanzó en 1999 su Programa Global contra la Corrupción, entre cuyos objetivos estaba la aprobación de instrumentos internacionales en esta materia ${ }^{20}$. Con la llegada del nuevo milenio se adoptó la Convención de las Naciones Unidas contra la delincuencia organizada transnacional $(2000)^{21}$, en la que, entre otras cosas, se insta a los Estados

${ }_{18}$ Sobre el bien jurídico lesionado por esta modalidad delictiva, vid. ampliamente, con referencias, BENITO SÁNCHEZ, D., El delito de corrupción en las transacciones comerciales internacionales, Iustel, Madrid, 2012, pp.165-176.

19 FABIÁN CAPARRÓs, E. A., La corrupción de agente público extranjero e internacional, op. cit., p. 89; Rodríguez Puerta, M. a J., «Capítulo X. De los delitos de corrupción en las transacciones internacionales», en Quintero Olivares, G. (Dir.) y Morales Prats, F. (Coord.), Comentarios a la Parte Especial del Código Penal, $5^{\text {a }}$ edición, Aranzadi, Elcano, 2005, p. 1726.

${ }^{20}$ Cuesta Arzamendi, J. L. de la, «Iniciativas internacionales contra la corrupción», en Cuesta ARZAmendi, J. L. de la et al., Justicia social y Derechos Humanos en la era de la globalización y la multiculturalidad, LXVI Curso Internacional de Criminología, Cuaderno del Instituto Vasco de Criminología, San Sebastián, n 12, 2003, p. 23.

${ }^{21}$ Entró en vigor de forma general y para España el 29 de septiembre de 2003 (BOE $\mathrm{n}^{\circ} 233$ de 29 de septiembre de 2003. 
miembros a tipificar como delito la corrupción activa y pasiva, ya sea de funcionarios nacionales, ya sea de funcionarios extranjeros o internacionales, si bien respecto de estos dos últimos tal disposición no es obligatoria sino sólo facultativa. Con todo, la Asamblea General de la ONU consideró necesario contar con un documento específico en materia la corrupción. Así, a finales de 2003 se adoptaba la Convención de Naciones Unidas contra la corrupción (en adelante, CNUCC) ${ }^{22}$.

$\mathrm{El}$ art. 16 de la mencionada convención se refiere a la corrupción transnacional. El párrafo primero obliga a castigar la corrupción activa de funcionarios públicos extranjeros e internacionales, siempre que esté vinculada con la realización de actividades comerciales internacionales, en la misma línea que la FCPA y el Convenio OCDE. El párrafo segundo se refiere a la corrupción pasiva, si bien, con dos diferencias esenciales respecto del anterior párrafo:

- La tipificación de la corrupción pasiva no es obligatoria. Simplemente, cada Estado «considerará la posibilidad» de hacerlo. La explicación a esta diferencia de trato viene dada por el hecho de que tipificar el cohecho pasivo de los funcionarios nacionales sí es obligatorio, luego si cada Estado cumple con esta obligación, no sería necesario que un Estado se ocupara de castigar el cohecho pasivo protagonizado por un funcionario de otro Estado pues este otro Estado ya lo castigaría ${ }^{23}$.

- La tipificación de estas conductas no está supeditada a la realización de actividades comerciales internacionales. Esta diferencia de trato nos indica que el castigo del funcionario no se fundamenta en la afectación al ya mencionado bien jurídico «competencia leal en el mercado internacional», sino en la afectación al clásico bien jurídico tutelado a través de los tipos penales del cohecho, el «correcto funcionamiento de la Administración Pública» ${ }^{24}$, si bien, en estos supuestos, se trataría de la Administración Pública de otros Estados o de organizaciones internacionales ${ }^{25}$.

${ }^{22}$ Resolución 58/4 de la Asamblea General de las Naciones Unidas de 31 de octubre de 2003. Entró en vigor de forma general el 14 de diciembre de 2005 y para España el 19 de julio de 2006 (BOE n 171 de 19 de julio de 2006).

${ }^{23}$ NaCiOnes UnidAs, Guía Legislativa para la aplicación de la Convención de Naciones Unidas contra la Corrupción, Oficina de Naciones Unidas contra la droga y el delito, División para asuntos de tratados, Nueva York, 2006, parágrafo 273.

${ }^{24}$ Sobre el bien jurídico en los delitos de cohecho clásico, vid. ampliamente, OlaizoLa Nogales, I., El delito de cohecho, Tirant lo Blanch, Valencia, 1999, pp. 79 y ss.; RoDríguez Puerta, M. ${ }^{a}$ J., El delito de cohecho. Problemática jurídico penal del soborno de funcionarios, Aranzadi, Pamplona, 1999, pp. 35 y ss.; Vizueta Fernández, J., Delitos contra la Administración Pública: estudio crítico del delito de cohecho, Comares, Granada, 2003, pp. 51 y ss.

${ }_{25}$ Benito SÁNCHEZ, D., El delito de corrupción en las transacciones comerciales internacionales, op. cit., pp. 217 y ss. 
En el ámbito europeo deben destacarse las iniciativas procedentes de dos organizaciones: la Unión Europea y el Consejo de Europa. En ambos casos, el tratamiento de la corrupción transnacional es diferente que el otorgado en los instrumentos anteriormente comentados. En primer lugar, mientras que en el Convenio OCDE y en la CNUCC (sólo en lo relativo a la corrupción activa) la conducta de soborno debe estar vinculada a la realización de actividades comerciales internacionales, en los instrumentos europeos no se exige dicha vinculación en absoluto, de modo tal que deberá será considerada como delito cualquier entrega de un soborno, ya persigue la obtención de un contrato, la omisión de una inspección, la no imposición de una multa de tráfico, etc. La segunda gran diferencia radica en el hecho de que los instrumentos europeos sí exigen el castigo de la corrupción pasiva transnacional, es decir, de la corrupción llevada a cabo por el funcionario del otro Estado. De nuevo, la razón para exigir el castigo de estos otros comportamientos parece estar relacionada con el hecho de que ya no se pretende tutelar la competencia leal en el mercado mundial, sino el correcto funcionamiento de la Administración Pública (aunque sea de otros Estados o de organizaciones internacionales).

Comentar, o si quiera, mencionar todas las iniciativas europeas en materia de corrupción excedería los límites razonables del presente trabajo ${ }^{26}$. Por eso sólo se apuntarán las más relevantes. La verdadera lucha contra la corrupción en la Unión Europea comienza con la adopción del Primer Protocolo Adicional al Convenio relativo a la protección de los intereses financieros de las Comunidades Europeas ${ }^{27}$. En el protocolo se exige la tipificación del cohecho activo y pasivo de funcionarios públicos nacionales, comunitarios y de Estados miembros de la Unión, si bien, cuando tales conductas «causen o puedan causar perjuicio a los intereses financieros de las Comunidades Europeas». No obstante, la necesidad de otorgar un tratamiento más amplio al problema de la corrupción motivó la adopción del documento más relevante en materia de corrupción en la UE, el Convenio relativo a la lucha contra los actos de corrupción en los que estén implicados funcionarios de las Comunidades Europeas o de los Estados miembros de la Unión Euro-

26 Vid. ampliamente al respecto, CARrera Hernández, F. J., «La persecución penal de la corrupción en la Unión Europea», en Vv.AA., Cooperación jurídica internacional, Madrid, 2001, pp. 207-234; Iglesias Río, M. A. y Medina Arnáiz, T., «Herramientas preventivas en la lucha contra la corrupción en el ámbito de la Unión Europea», Revista Penal, no 14, Julio 2004, pp. 49-69.

${ }^{27}$ Protocolo establecido sobre la base del artículo K.3 del Tratado de la Unión Europea, del Convenio relativo a la protección de los intereses financieros de las Comunidades Europeas, de 27 de septiembre de 1996. Entró en vigor de forma general y para España el 17 de octubre de 2002 (DOCE $n^{\circ}$ C 313 , de 23 de octubre; BOE n $^{\circ} 180$ de 29 de julio de 2003, corrección de errores: BOE n 233 de 29 de septiembre de 2003). 
pea $^{28}$ (en adelante, Convenio UE). Inspirado en el Primer Protocolo, este Convenio tiene un ámbito de aplicación mayor, ya que exige castigar el cohecho activo y pasivo de funcionarios nacionales, comunitarios y de otros Estado miembros de la Unión sin limitarse a supuestos que lesionen los intereses financieros de la Unión.

El Convenio UE, como no podía ser de otro modo, se circunscribe al ámbito comunitario, no exigiéndose el castigo del cohecho de funcionarios de otras organizaciones internacionales ni de funcionarios de otros Estados que no sean miembros de la Unión.

El Consejo de Europa, por su parte, reunido en su $19^{\text {a }}$ Conferencia de Ministros de Justicia en 1994, manifestó su deseo de luchar contra la corrupción, para lo cual, creó un grupo multidisciplinar encargado de elaborar un programa de acción contra la corrupción ${ }^{29}$. Dicho programa se adoptó en 1996 y en él se contenía la recomendación de redactar un convenio internacional en la materia. Finalmente, no fue sólo uno, sino dos: el Convenio penal sobre la corrupción $^{30}$, y el Convenio civil sobre la corrupción ${ }^{31}$, ambos de 1999.

En materia de corrupción transnacional, el Convenio penal del Consejo de Europa es sin duda el más amplio de todos los documentos supranacionales e internacionales existentes. Así, exige castigar como delito las conductas de corrupción activa y pasiva de funcionarios públicos de otros Estados, de miembros de asambleas parlamentarias de otros Estados, de funcionarios de una organización pública internacional o supranacional en la que el Estado sea parte, de miembros de asambleas parlamentarias de una organización internacional o supranacional en la que el Estado sea parte, y de personas que ejerzan funciones judiciales en un tribunal internacional o de funcionarios de la secretaría de dicho tribunal cuya competencia sea aceptada por el Estado parte.

${ }^{28}$ Convenio establecido sobre la base de la letra c del apartado 2 del artículo K.3 del Tratado de la Unión Europea relativo a la lucha contra los actos de corrupción en los que estén implicados funcionarios de las Comunidades Europeas o de los Estados miembros de la Unión Europea, de 26 de mayo de 1997 Entró en vigor de forma general y para España el 28 de septiembre de 2005 (DOCE n ${ }^{\circ}$ C 195, de 25 de junio; BOE n 74 de 28 de marzo de 2006).

29 Ampliamente, sobre las iniciativas contra la corrupción procedentes del Consejo de Europa, LezertuA, M., «Council of Europe: an overview of Anti-Corruption Activities from 1994 to 1998», Pieth, M.y EIgen, P. (Ed.), Korruption im internationalen Geschäftsverkehr. Bestandsaufnahmen, Bekämpfung, Prävention, Ed. Luchternahd, Frankfurt am Main, 1998, pp. 228-229.

${ }^{30}$ El Convenio penal entró en vigor, de forma general, el 1 de julio de 2002, y para España el 1 de agosto 2010 (BOE no 182 de 28 de julio de 2010).

${ }^{31}$ El Convenio civil entró en vigor, de forma general, el 1 de noviembre de 2003, y para España, el 1 de abril de 2010 (BOE nº 78 de 31 de marzo de 2010). 


\subsection{Resumen de las obligaciones impuestas a España en materia de corrupción transnacional}

España se encuentra vinculada en el momento actual por todos los instrumentos internacionales mencionados, salvo por la Convención interamericana, por razones evidentes ${ }^{32}$. Tales instrumentos imponen a los Estados parte el castigo de la corrupción tanto pública como privada, y dentro de la prime$\mathrm{ra}$, tanto la corrupción de funcionarios nacionales como la de funcionarios de otros Estados y organizaciones internacionales. Sin embargo, existen matices entre los diferentes instrumentos a la hora de exigir la tipificación, como en líneas generales se ha señalado anteriormente.

Simplificando, las obligaciones de carácter penal asumidas por nuestro país en materia de corrupción transnacional son las siguientes:

- Convenio OCDE y CNUCC. Obligación de tipificar el cohecho activo de funcionarios públicos extranjeros y de organizaciones internacionales cuando acontezca en el marco de actividades comerciales internacionales.

- Convenio UE. Obligación de tipificar el cohecho activo y pasivo de funcionarios públicos comunitarios y de otros Estados miembros de la UE.

- Convenio penal del Consejo de Europa. Obligación de tipificar el cohecho activo y pasivo de funcionarios públicos de otros Estados (incluidos miembros de asambleas parlamentarias), de funcionarios públicos de organizaciones internacionales en las que España sea parte (incluidos miembros de asambleas parlamentarias internacionales), y de funcionarios de tribunales internacionales cuya jurisdicción haya aceptado España.

\section{LA INCORPORACIÓN AL CÓDIGO PENAL ESPAÑOL DEL DELITO DE CORRUPCIÓN EN LAS TRANSACCIONES COMERCIALES INTERNACIONALES}

La ratificación por España del Convenio OCDE exigía la incorporación a nuestro Derecho de un nuevo tipo penal que castigara el cohecho activo de funcionarios públicos de otros Estados y de organizaciones internacionales en las transacciones comerciales internacionales. Para dar cumplimiento a tal exigencia, la Ley Orgánica 3/2000, de 11 de enero ${ }^{33}$, incorporó al texto punitivo un novedoso art. 445 bis a un nuevo Título, el XIX bis, denominado «De

${ }^{32}$ Con todo, la Convención interamericana está abierta a la adhesión por cualquier Estado, no sólo los pertenecientes a la Organización de Estados Americanos (art. XXIII de la convención).

${ }_{33}$ Ley Orgánica 3/2000, de 11 de enero, de modificación de la Ley Orgánica 10/1995, de 23 de noviembre, del Código Penal, en materia de lucha contra la corrupción de agen- 
los delitos de corrupción en las transacciones comerciales internacionales», ubicado inmediatamente detrás del Título dedicado a los «Delitos contra la Administración Pública».

La explicación para la ubicación del delito en ese lugar tiene que ver el bien jurídico lesionado por estas conductas, como se reflejó en los debates parlamentarios de la nueva norma. Así, mientras que el proyecto inicial de reforma pretendía incorporar este delito dentro de un párrafo tercero del entonces art. 423 (que regulaba el cohecho activo de funcionarios nacionales), el Grupo Parlamentario de Senadores Nacionalistas Vascos presentó una enmienda argumentando que sería más correcto introducir un título nuevo y aparte, por ser el bien jurídico lesionado no la Administración Pública española, «sino un bien jurídico distinto, un cierto orden internacional en las transacciones económicas ${ }^{34}$, bien jurídico a tutelar perfectamente diferenciado del protegido en el Título XIX. Teniendo esto en consideración, el nuevo precepto del nuevo título quedó redactado de la siguiente manera:

«Los que, con dádivas, presentes, ofrecimientos o promesas, corrompieran o intentaran corromper, por sí o por persona interpuesta, a las autoridades o funcionarios públicos extranjeros o de organizaciones internacionales en el ejercicio de su cargo en beneficio de éstos o de un tercero, o atendieran a sus solicitudes al respecto, con el fin de que actúen o se abstengan de actuar en relación con el ejercicio de funciones públicas para conseguir o conservar un contrato u otro beneficio irregular en la realización de actividades económicas internacionales, serán castigados con las penas previstas en el artículo 423, en sus respectivos casos».

En el año 2003, aprovechando la profunda reforma del texto punitivo que llevó a cabo la Ley Orgánica 15/2003, de 25 de noviembre ${ }^{35}$, se realizaron las siguientes modificaciones en el art. 445 bis. Por un lado, el art. 445 bis pasó a ser el párrafo primero del art. 445 -el cual había quedado vacío de contenido- y se añadió a dicho precepto un párrafo segundo, con el siguiente tenor literal:

tes públicos extranjeros en las transacciones comerciales internacionales $\left(\mathrm{BOE} \mathrm{n}^{\circ} 10\right.$, de 12 de Enero de 2000).

34 Vid. BOCG, Congreso de los Diputados, Diario de Sesiones, Pleno y Diputación permanente, VI Legislatura, año 1999, $\mathrm{n}^{\mathrm{o}} 277$, sesión plenaria ${ }^{\circ} 267$ celebrada el 25 de noviembre de 1999, p. 14963. En el mismo sentido se pronunció el Grupo Catalán (Convergencia i Unió), en cuyo nombre, el Sr. GUANDANS I CAMBÓ señaló la conveniencia de crear «un título distinto que hable del buen orden económico mundial o algo por el estilo, puesto que ése es el bien jurídico protegido». Vid. BOCG, Congreso de los Diputados, Diario de Sesiones, Pleno y Diputación permanente, VI Legislatura, año 1999, no 277, sesión plenaria ${ }^{\circ} 267$ celebrada el 25 de noviembre de 1999, p. 14964.

${ }_{35}$ Ley Orgánica 15/2003, de 25 de noviembre, por la que se modifica la Ley Orgánica 10/1995, de 23 de noviembre, del Código Penal (BOE nº 183, de 26 de noviembre de 2003). 
«Si el culpable perteneciere a una sociedad, organización o asociación, incluso de carácter transitorio, que se dedicare a la realización de estas actividades, el juez o tribunal podrá imponer alguna o algunas de las consecuencias previstas en el artículo 129 de este Código».

Por otro lado, el reformado art. 445, con sus dos párrafos, pasó a integrar un nuevo Capítulo X, denominado «De los delitos de corrupción en las transacciones comerciales internacionales», dentro del Título XIX «De los delitos contra la Administración Pública».

Estas modificaciones no fueron justificadas en la Exposición de Motivos de la mencionada ley, la cual omitió cualquier referencia a la corrupción transnacional. El cambio de ubicación fue, sin duda, un desacierto puesto que al incorporarlo al Título XIX parecía indicarse que el bien jurídico lesionado está en íntima relación con la Administración Pública española y, como ya se ha indicado, no es así dado que el funcionario público implicado en el acto de corrupción desempeña sus funciones para una Administración Pública de otro Estado o de una organización internacional.

Por otra parte, la inclusión del párrafo segundo se debe al hecho de que el grupo de trabajo sobre soborno de la OCDE, en la evaluación realizada a España en el año $2000^{36}$, señalara que nuestro país no estaba cumplimiento con el convenio en lo relativo a la responsabilidad de las personas jurídicas por su implicación en estos delitos ${ }^{37}$.

La tercera modificación del delito de corrupción transnacional se produjo en 2010, de nuevo, aprovechando la reforma integral del texto punitivo realizada por Ley Orgánica 5/2010, de 22 de junio ${ }^{38}$. La Exposición de Motivos de la ley apuntaba al cumplimiento de las recomendaciones hechas por el grupo de trabajo de la OCDE en las diversas evaluaciones que había sometido a nuestra legislación ${ }^{39}$. En general, se demandaba una mejor redacción que

${ }^{36}$ OCDE (Grupo de trabajo sobre soborno), Spain. Review of implementation of the Convention and 1997 Recommendation, de 2000.

37 Téngase en cuenta el art. 2 del Convenio, que señala lo siguiente: «Responsabilidad de las personas jurídicas. Cada Parte tomará las medidas que sean necesarias, de conformidad con sus principios jurídicos, para establecer la responsabilidad de las personas jurídicas por la corrupción de un agente público extranjero»; y el art. 3.2 del mismo texto: «En caso de que, según el ordenamiento jurídico de una Parte, la responsabilidad penal no sea aplicable a las personas jurídicas, esa Parte velará por que éstas estén sujetas a sanciones eficaces, proporcionadas y disuasorias de carácter no penal, incluidas las sanciones pecuniarias, por la corrupción de agentes públicos extranjeros».

38 Ley Orgánica 5/2010, de 22 de junio, por la que se modifica la Ley Orgánica 10/1995, de 23 de noviembre, del Código Penal (BOE n 152, de 23 de junio de 2010).

39 Véanse dichas recomendaciones en los siguientes informes: OECD (Working Group on Bribery), Spain. Phase 2. Follow-up report on the implementation of the phase 2 recommendations on the applications of the Convention and the 1997 Revised Recommen- 
no vinculara el art. 445 con el art. 423 (que albergaba el delito de cohecho activo de funcionarios nacionales), la incorporación de una definición de funcionario público extranjero e internacional, y la responsabilidad penal de las personas jurídicas. El nuevo precepto rezaba así:

«1. Los que mediante el ofrecimiento, promesa o concesión de cualquier beneficio indebido, pecuniario o de otra clase, corrompieren o intentaren corromper, por si o por persona interpuesta, a los funcionarios públicos extranjeros o de organizaciones internacionales, en beneficio de estos o de un tercero, o atendieran sus solicitudes al respecto, con el fin de que actúen o se abstengan de actuar en relación con el ejercicio de funciones públicas para conseguir o conservar un contrato $u$ otro beneficio irregular en la realización de actividades económicas internacionales, serán castigados con las penas de prisión de dos a seis años y multa de doce a veinticuatro meses, salvo que el beneficio obtenido fuese superior a la cantidad resultante, en cuyo caso la multa será del tanto al duplo del montante de dicho beneficio.

Además de las penas señaladas, se impondrá al responsable la pena de prohibición de contratar con el sector público, así como la pérdida de la posibilidad de obtener subvenciones o ayudas públicas y del derecho a gozar de beneficios o incentivos fiscales y de la Seguridad Social, y la prohibición de intervenir en transacciones comerciales de trascendencia pública por un periodo de siete a doce años.

Las penas previstas en los párrafos anteriores se impondrán en su mitad superior si el objeto del negocio versara sobre bienes o servicios humanitarios o cualesquiera otros de primera necesidad.

2. Cuando de acuerdo con lo establecido en el artículo 31 bis de este Código una persona jurídica sea responsable de este delito, se le impondrá la pena de multa de dos a cinco años, o la del triple al quíntuple del beneficio obtenido si la cantidad resultante fuese más elevada.

Atendidas las reglas establecidas en el artículo 66 bis, los jueces y tribunales podrán asimismo imponer las penas recogidas en las letras b) a g) del apartado 7 del artículo 33 .

3. A los efectos de este artículo se entiende por funcionario público extranjero:

a. Cualquier persona que ostente un cargo legislativo, administrativo o judicial de un país extranjero, tanto por nombramiento como por elección.

dation on Combating bribery of foreign public officials in international business transactions, OECD Publications, 2008; OECD (Working Group on Bribery), Spain. Phase 2. Report on the application of the Convention on Combating bribery of foreign public officials in international business transactions and the 1997 Recommendation on Combating bribery in international business transactions, OECD Publications, 2006; OECD (Working Group on Bribery), Spain. Review of implementation of the Convention and 1997 Recommendation, OECD Publications, 2000. 
b. Cualquier persona que ejerza una función pública para un país extranjero, incluido un organismo público o una empresa pública. pública.»

c. Cualquier funcionario o agente de una organización internacional

Esta misma ley de 2010 sirvió para dar cumplimiento al Convenio UE de 1997, antes referido, pues pese a haber entrado en vigor en 2005, España no había adaptado su legislación al mismo. Recuérdese que éste obligaba a los Estados miembros a castigar como delito el cohecho activo y pasivo de funcionarios nacionales, comunitarios y de otros Estados miembros de la Unión. Hasta ese momento, la definición recogida en el art. 24 del código penal sólo incluía a los miembros del Parlamento Europeo, pero no al resto de funcionarios de los diversos organismos de la UE, luego nuestra legislación era a todas luces insuficiente para cumplir el convenio. Además, nada se decía en nuestro código penal acerca de los funcionarios de otros Estados miembros de la Unión Europea. La reforma de 2010 incorporó un nuevo precepto al texto punitivo, el art. 427, cuyo párrafo primero hace extensibles los tipos penales de cohecho activo y pasivo (de funcionarios nacionales) a los hechos que impliquen a «funcionarios de la Unión Europea o a los funcionarios nacionales de otro Estado miembro de la Unión», y además, ofrece una definición auténtica de tal expresión; reproducción literal de la que parece en el Convenio UE.

Pese a esta modificación de 2010, España seguía sin cumplir con los compromisos asumidos al ratificar el Convenio penal sobre la corrupción del Consejo de Europa pues éste, como se ha indicado, exige la tipificación de conductas que bajo la reforma de 2010 no se introdujeron, a saber, el cohecho activo y pasivo de funcionarios públicos extranjeros y de organizaciones internacionales no vinculado a las transacciones comerciales internacionales, más allá de los funcionarios del ámbito comunitario.

\section{EL DELITO DE CORRUPCIÓN EN LAS TRANSACCIONES COMERCIALES INTERNACIONALES EN EL NUEVO ART. 286 TER}

La recién aprobada Ley Orgánica 1/2015, de 30 de marzo, por la que se modifica la Ley Orgánica 10/1995, de 23 de noviembre, del Código Penal ${ }^{40}$ ha previsto una serie de modificaciones en el delito de corrupción en las transacciones comerciales internacionales con el objetivo de «garantizar la aplicación de estos preceptos», tal y como señala su exposición de motivos. Las modificaciones son, sin duda, novedosas y muchas de ellas controvertidas, pues van desde el cambio de ubicación del precepto a otro título del texto

\footnotetext{
${ }^{40}$ BOE n $^{\circ} 77$ de 31 de marzo de 2015.
} 
punitivo hasta la eliminación de la necesidad de que el funcionario público desempeñe sus funciones para otro Estado o para una organización internacional, característica esencial de esta modalidad delictiva no sólo desde que se incorporara a nuestro Derecho en el año 2000, sino desde sus orígenes en la FCPA norteamericana y en todos los instrumentos internacionales que abordan esta materia. Además, se realizan algunas otras modificaciones menores del tipo penal.

En concreto, el contenido del actual art. 445 pasa a ser el nuevo art. 286 ter, dentro de la Sección $4^{\mathrm{a}}$ del Capítulo XI del Título XIII del Libro II, sección que pasa a denominarse «De la corrupción en el sector privado». El futuro art. 286 ter señala lo siguiente:

«1. Los que mediante el ofrecimiento, promesa o concesión de cualquier beneficio o ventaja indebidos, pecuniario o de otra clase, corrompieren o intentaren corromper, por sí o por persona interpuesta, a una autoridad o funcionario público, en beneficio de estos o de un tercero, $o$ atendieran sus solicitudes al respecto, con el fin de que actúen o se abstengan de actuar en relación con el ejercicio de funciones públicas para conseguir o conservar un contrato, negocio o cualquier otra ventaja competitiva en la realización de actividades económicas internacionales, serán castigados, salvo que ya lo estuvieran con una pena más grave en otro precepto de este Código, con las penas de prisión de prisión de tres a seis años, multa de doce a veinticuatro meses, salvo que el beneficio obtenido fuese superior a la cantidad resultante, en cuyo caso la multa será del tanto al triplo del montante de dicho beneficio.

Además de las penas señaladas, se impondrá en todo caso al responsable la pena de prohibición de contratar con el sector público, así como la pérdida de la posibilidad de obtener subvenciones o ayudas públicas y del derecho a gozar de beneficios o incentivos fiscales y de la Seguridad Social, y la prohibición de intervenir en transacciones comerciales de trascendencia pública por un periodo de siete a doce años.

2. A los efectos de este artículo se entenderá por funcionario público los determinados por los artículos 24 y 427.»

Por su parte, el art. 427 -recuérdese que hasta la aprobación de la Ley Orgánica 1/2015 regulaba lo que podríamos llamar cohecho en el ámbito comunitario-, hace extensibles los tipos penales de cohecho de funcionarios nacionales a los hechos relacionados con funcionarios públicos de Estados miembros de la Unión Europea o de cualquier otro país, y a los funcionarios de la propia Unión Europea o de otras organizaciones internacionales públicas. A través de esta modificación, el legislador español ha dado cumplimiento al Convenio penal sobre la corrupción del Consejo de Europa.

Este trabajo, en los siguientes apartados, se centrará en el análisis de las modificaciones realizadas en el delito de corrupción en transacciones comerciales internacionales del nuevo art. 286 ter. 


\subsection{Cambio de ubicación y bien jurídico}

El bien jurídico cumple una función de sistematización en el código penal, luego la ubicación de un precepto en un lugar o en otro lleva a reflexionar sobre cuál es el objeto jurídico que se vulnera al realizar la conducta típica.

El delito de corrupción de funcionarios públicos extranjeros en las transacciones comerciales internacionales se ubicó inicialmente, como se ha señalado, fuera del Título XIX precisamente por entenderse que lesionaba un bien jurídico que nada tenía que ver con la Administración Pública española, a saber, la competencia leal en el mercado mundial. La reubicación del precepto dentro del Título XIX en 2003 y su mantenimiento ahí hasta la aprobación de la Ley Orgánica 1/2015 era, sin duda, injustificada por razón del bien jurídico tutelado; de ahí que fuera necesario encontrarle otro lugar en el texto punitivo.

La inclusión del nuevo art. 286 ter dentro del Título XIII es acertada, pues estamos ante un delito contra el orden socioeconómico ${ }^{41}$. De hecho, este

${ }^{41}$ Desde su incorporación al texto punitivo, la doctrina ha debatido cuál es el bien jurídico lesionado por estas conductas. Buena parte de la doctrina se posiciona señalando que el bien jurídico tutelado es de carácter socioeconómico, en concreto, la competencia leal en el mercado internacional. Vid. entre otros, Demetrio CresPo, E., «Consideraciones sobre la corrupción y los delitos contra la Administración Pública», en FERRÉ OLIVÉ, J.C., Fraude y corrupción en la Administración Pública, Salamanca. Edic. Universidad Salamanca, 2003; p. 184; DíAz-MAROto Y VilLAREJo, J., «El delito de corrupción en las transacciones comerciales internacionales (art. 445 del Código penal) (1)», La Ley, $\mathrm{n}^{\circ} 3$, 2007; FABIÁN CAPARRÓs, E. A., La corrupción de agente público extranjero e internacio-

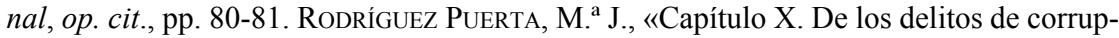
ción en las transacciones internacionales», op. cit., p. 1725. Pronunciándose en el mismo sentido, aunque comentando el Derecho alemán, Nestler, C., «Amtsträgerkorruption gemäss $§ 335$ a (Entwurf) StGB», en $S t V$, mayo de 2009, p. 315. No obstante, hay quien entiende que lo que aquí se trata de tutelar es el correcto funcionamiento de la Administración Pública extranjera. Vid., Acale SÁnchez, M., «Lección 24. Delitos contra la Administración Pública (II)», en TERRADILlos BASOCO, J. M., Lecciones y materiales para el estudio del Derecho penal, Tomo III, Derecho penal, Parte Especial, Volumen II, Iustel, 2011, 190: Olaizola Nogales, I., «Delitos de corrupción en las transacciones comerciales internacionales», en LuZÓN PEÑA, D. M., Enciclopedia penal básica, Comares, Granada, 2002, pp. 477; Serrano Gómez, A. y Serrano Maillo, A., Derecho penal. Parte especial, $13^{\mathrm{a}}$ edición, Dykinson, Madrid, 2008, p. 860, si bien junto al normal funcionamiento de la Administración Pública añade el normal funcionamiento de las organizaciones internacionales. En un tercer grupo, se ubican aquéllos que consideran que estamos ante un delito pluriofensivo, que lesiona tanto la competencia leal en el mercado internacional como el correcto funcionamiento de la Administración Pública, CóRDOBA RoDA, J. y García Arán, M. (Dir.), Comentarios al Código penal. parte especial. Tomo I, op. cit., p. 2117; Cuesta Arzamendi, J. L. de la y Blanco Cordero, I., «Los nuevos delitos de corrupción en las transacciones comerciales internacionales», Revista de Ciencias Penales, vol. 4, 2001-2002, p. 12; NIETO MARTín, A., «La corrupción en el sector privado (re- 
cambio de ubicación ya había sido demandado por parte de la doctrina ${ }^{42}$. Más en concreto, la ubicación en el Capítulo XI («De los delitos relativos a la propiedad intelectual e industrial, al mercado y a los consumidores») también debe considerarse acertada, pues se trata de una conducta contra el mercado y los consumidores. Dentro de este capítulo, ha optado el legislador español por modificar el intitulado de la actual Sección $4^{\mathrm{a}}$, pasándose a denominar «Delitos de corrupción en las negocios», en lugar de la actual denominación «De la corrupción entre particulares», para poder ubicar en ella el nuevo tipo penal. El cambio de nomenclatura era necesario pues el delito que aquí nos ocupa difícilmente podría enmarcarse dentro de lo que desde años se viene llamando «corrupción privada» o "corrupción entre particulares», ya que en el delito aquí estudiado es imprescindible la presencia de un funcionario público que actúe «en relación con el ejercicio de funciones públicas», lo que aleja estas conductas del ámbito privado para situarlas en el ámbito público, ello a pesar de que en el momento presente sea en ocasiones difícil separar uno del otro. La nueva rúbrica es lo suficientemente amplia como para englobar el delito de corrupción en transacciones comerciales internacionales y el delito de corrupción privada ${ }^{43}$, con el que comparte bien jurídico tutelado.

\subsection{La eliminación de la expresión "[funcionarios públicos] extranjeros o de organizaciones internacionales» y las consecuencias concursales}

Esta modificación es, sin duda, una de las más llamativas de la reforma operada por la Ley Orgánica 1/2015, de 30 de marzo, pues la expresión suprimida constituía la esencia de este tipo penal y era lo que le distinguía del cohecho clásico, el que se aplica cuando los funcionarios involucrados son nacionales. Es el propio art. 286 bis, en su párrafo segundo, el que señala qué ha de entenderse por funcionario público, remitiéndose en este punto a los

flexiones desde el ordenamiento español a la luz del Derecho comparado), Revista Penal $\mathrm{n}^{\circ}$ 10, 2002; p. 61; STESSENS, G., «The international fight against corruption. General Report», Revue Internationale de Droit Pénal, vol. 72, 3-4, 2001 ; pp. 910 y 913. También el Explanatory report del Convenio penal sobre la corrupción del Consejo de Europa señala que en el caso del soborno a funcionarios públicos extranjeros hay dos intereses a proteger: uno, «la transparencia y la imparcialidad en el proceso de toma de decisiones de Administraciones Públicas extranjeras» y otro, «proteger la competencia leal en los negocios». Consejo De Europa: Explanatory Report on the Criminal Law Convention on Corruption, Council of Europe Press, Estrasburgo, 1999, párrafo 48.

${ }_{42}$ Benito SÁnchez, D., El delito de corrupción en las transacciones comerciales internacionales, op. cit., p. 175; RodríGuez PuerTA, M. ${ }^{a}$ J., "Capítulo X. De los delitos de corrupción en las transacciones internacionales», op. cit. p. 1725.

${ }^{43}$ Incorporado al texto punitivo a través de la Ley Orgánica 5/2010, de 22 de junio. 
arts. 24 y 427 del texto punitivo. Teniendo en cuenta dichos preceptos, se van a incluir los funcionarios nacionales, los de terceros Estados (incluidos Estados miembros de la UE) y los de organizaciones internacionales pública (incluida la UE).

Respecto de los primeros surge el siguiente problema ¿Se tendrá que incluir en este precepto el pago de un soborno a un funcionario español si va dirigido a la obtención de un contrato en el marco de una relación comercial internacional? En principio, sí tendrá cabida; pero también tendrá cabida en el delito de cohecho activo clásico del art. 424, luego lo que ha hecho aquí el legislador ha sido crear un nuevo problema no presente en la regulación anterior: un concurso, al que ha pretendido dar solución a través de la cláusula «salvo que ya lo estuvieran [castigados] con una pena más grave en otro precepto de este Código» ${ }^{44}$.

La pregunta que a continuación nos podemos hacer es la siguiente: ¿se castiga con más pena esta conducta en otro precepto de este Código? Para contestar a esta pregunta es preciso acudir al art. 424, el cual se remite a las penas de los delitos de cohecho pasivo. Si es propio (art. 419), la pena será de prisión de tres a seis años y de multa de 12 a 24 meses; y si es impropio (art. 420), la pena será de prisión de dos a cuatro años y de multa de 12 a 24 meses.

La solución al problema planteado será la siguiente:

- Si se trata de cohecho propio, tanto el art. 286 ter como el art. 419 prevén igual pena, luego la regla concursal incorporada en el art. 286 ter no es de utilidad y habremos de acudir a las reglas sobre el concurso de leyes del art. 8 del código penal. En este caso, debería resolverse el concurso de leyes en virtud del principio de especialidad, y la ley especial será la contenida en el art. 286 ter.

- Si se trata de cohecho impropio, la pena mayor es la del art. 286 ter, luego se aplicaría este precepto.

Por tanto, la inclusión de esta cláusula, como se ha visto, no resuelve el problema cuando estemos ante cohecho propio. Pero además, esta nueva regulación implica una diferencia de trato del cohecho impropio sobre funcionarios españoles dependiendo de cuál sea la finalidad del soborno: si está relacionado con actividades comerciales internaciones la pena será de prisión de tres a seis años; si no lo está, la pena de prisión será de dos a cuatro años. Es difícil justificar este diferente tratamiento a menos que se haga hincapié en

${ }^{44}$ La exposición de motivos de la nueva ley indica que con tal expresión «se solucionan las dificultades que pudiera plantear la concurrencia de esta norma con las que regulan el cohecho en el Código Penal». Reflexionando sobre los ejemplos expuestos puede afirmarse que el legislador ha conseguido precisamente lo contrario. 
la diversidad de bienes jurídicos (competencia leal en el comercio internacional, por un lado; y correcto funcionamiento de la Administración Pública española, por otro), pero siendo éste el caso, es decir, si la conducta del que soborna está vulnerando dos bienes jurídicos diferentes, se podría plantear aquí la aplicación de un concurso de delitos, y no, de un concurso de leyes, lo que en la práctica parece, sin embargo, de muy difícil aceptación.

Por otro lado, el nuevo art. 286 ter también puede entrar en concurso con el art. 427. La problemática ya acontecía antes de la aprobación de la Ley Orgánica 1/2015, de 30 de marzo, y continuará en el futuro cuando el art. 427 albergue no sólo el cohecho en el ámbito comunitario sino también el cohecho de funcionarios extranjeros o internacionales, en general. Piénsese en el siguiente ejemplo: un ciudadano español que entrega un soborno a un funcionario mexicano para obtener un contrato en el marco de la realización de actividades comerciales internacionales. Ambos preceptos son, en principio, aplicables. De nuevo, deberíamos acudir a la regla prevista en el art. 286 bis, y de nuevo la conclusión sería que debe aplicarse éste porque es el que prevé las penas mayores y, en caso de penas iguales (cohecho propio), el art. 286 bis es el precepto especial y, por tanto, el que se aplicará.

\subsection{La finalidad del soborno: "conseguir o conservar un contrato, negocio o cualquier otra ventaja competitiva»}

Desde su incorporación al texto punitivo, el delito de corrupción en las transacciones comerciales internacionales contiene un elemento subjetivo específico del injusto distinto del dolo que nos permite calificar este tipo penal como delito de tendencia interna trascendente ${ }^{45}$. Este elemento cumple una doble función. Por un lado, confirma cuál es el bien jurídico protegido $^{46}$-la competencia leal en el mercado internacional-; y por otro, limita el ámbito de aplicación del precepto, debiéndose declarar la atipicidad de la entrega de sobornos que no persiguen dicha finalidad, como por ejemplo, un soborno entregado a un funcionario público extranjero para evitar una multa de tráfico o para lograr una sentencia absolutoria respecto de un familiar en ese país.

En la redacción del nuevo art. 286 ter, el elemento subjetivo específico del injusto aparece redactado de la siguiente manera: «para conseguir o conservar un contrato, negocio o cualquier otra ventaja competitiva». La anterior

${ }^{45}$ FABIÁN CAPARRÓs, Eduardo A., La corrupción de agente público extranjero e internacional, op. cit., p. 112.

46 Cuesta Arzamendi, J. L. de la y Blanco Cordero, I., «Los nuevos delitos de corrupción en las transacciones comerciales internacionales», op. cit., p. 21; STESSENS, G., «The international fight against corruption. General Report», op. cit., pp. 902-903. 
redacción de este elemento en el tipo penal («conseguir o conservar un contrato $\mathrm{u}$ otro beneficio irregular en la realización de actividades comerciales internacionales») había suscitado algunos problemas, en especial, el término «beneficio irregular», que parecía una incorrecta traducción del art. 1.1 del Convenio $\mathrm{OCDE}^{47}$.

En la nueva redacción, debe valorarse de manera positiva el haber sustituido la voz «contrato» por «negocio», más acorde con la terminología empleada en los instrumentos supranacionales y que dará cobertura a un mayor número de conductas ${ }^{48}$. Asimismo, la sustitución de la expresión «beneficio irregular» por «cualquier otra ventaja competitiva» también es acertada dado que el término anterior «irregular» parecía excluir del tipo penal el cohecho impropio, pese a que la intención del Convenio OCDE es castigarlo. Con la nueva expresión se amplía el ámbito de lo punible a supuestos que no van directamente orientados a conseguir un negocio pero que pueden favorecerlo, como la reducción de tasas aduaneras u otro tipo de impuestos, o incluso la modificación de una legislación ${ }^{49}$.

\subsection{La pena}

El nuevo precepto eleva el marco penal que contenía el anterior art. 445. Así, de una pena de dos a seis años se pasa a una pena de tres a seis años, equiparándose a la prevista para el cohecho propio de funcionarios nacionales (art. 419). El Convenio OCDE exige el mismo tratamiento a la corrupción transnacional que a la corrupción nacional, y aparentemente, así se hace en el proyecto de reforma. Sin embargo, no debe olvidarse que respecto al cohecho nacional se prevén penas diferentes en función de si estamos ante cohecho propio o impropio. Estas distinciones no se prevén en el cohecho transnacional del nuevo art. 286 ter, como no se prevén en el actual art. 445.

Con todo, y teniendo en cuenta que según las indicaciones de la OCDE en su última Recomendación sobre soborno transnacional, del año $2009^{50}$, de-

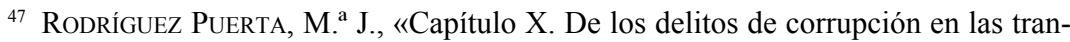
sacciones internacionales», op. cit., pp. 1727-1728.

48 SÁnchez Bernal, J., «Delincuencia de los poderosos y cohecho. Modificaciones previstas en la Proyecto de Ley Orgánica de Reforma del Código Penal de 2013», en PÉREZ CEPEDA, A. I. (Dir.) y GorJón BARRANCO, M. C. (Coord.), El proyecto de reforma del código penal de 2013 a debate, Ratio Legis, Salamanca, 2014, pp. 187-188.

49 En este mismo sentido se pronuncia la jurisprudencia estadounidense al aplicar la FCPA. Vid. OECD (Working Group on Bribery), Phase 3. Report on implementing the OECD Anti-Bribery Convention in the United States, OECD Publications, 2010, p. 27.

${ }_{50}$ Recomendación del Consejo para un mayor combate del cohecho de funcionarios públicos extranjeros en las transacciones comerciales internacionales (C (2009) 159). En ella se insta a los Estados parte en el Convenio de 1997 a que revisen su actual política en 
ben incluirse dentro del tipo penal los llamados pagos de facilitación o pagos de engrase ${ }^{51}$, esos que se entregan al funcionario público para acelerar trámites burocráticos, quizá la pena sea un tanto elevada, en particular, en su límite inferior pues incluso en estos casos de menor gravedad, no habrá posibilidad de eludir la entrada en prisión dado que no se prevé ningún tipo atenuado relacionado con la menor gravedad de la conducta.

\section{CONCLUSIONES Y PROPUESTAS DE LEGE FERENDA}

La nueva regulación del delito de corrupción en las transacciones comerciales internacionales dista de ser la más adecuada y no parece que vaya a contribuir a garantizar la aplicación de estos delitos, pese a que esa sea la intención del legislador -reflejada en la exposición de motivos de la nueva ley-, pues la aplicación de un precepto poco depende de la ubicación concreta en el código penal. Es altamente preocupante que en quince años de vigencia de este delito, no se haya aplicado en ninguna ocasión, y que únicamente se conozca la apertura de un escaso número de investigaciones que acabaron archivadas. Las modificaciones recientemente incorporadas al tipo penal no parece que vayan a solucionar este problema, el cual requeriría un refuerzo de los mecanismos de investigación, especialmente, de los relativos a la cooperación policial y judicial en el ámbito internacional, dado el carácter transnacional de la conducta, aparte de voluntad para perseguir estas conductas que atentan contra el orden socioeconómico mundial pese a que sirvan para incrementar el volumen de negocio de las empresas nacionales, objetivo que puede parecer legítimo siempre, y más aún en un momento de crisis económica como la actual. No obstante, planteamientos egoístas como éstos no pueden tener cabida en la aldea global.

Aparte de esas modificaciones de índole procesal, también en el ámbito del Derecho penal sustantivo son deseables algunas reformas, si quiera sea, para facilitar la aplicación del precepto, no ya para garantizarla, y para adaptar el tipo penal a los requerimientos internacionales. Así, de lege ferenda

relación con los pequeños pagos de facilitación dados los efectos corrosivos que éstos generan, particularmente, «sobre el desarrollo económico sostenible y sobre el Estado de Derecho»; y a que «prohíban o ahuyenten a las empresas del uso de estos pagos (...) reconociendo que suelen ser ilegales en los países en donde se hacen».

${ }^{51}$ Los pagos de facilitación fueron inicialmente excluidos del ámbito de aplicación del Convenio OCDE, siempre que fueran «pequeños». Véanse los Comentarios al Convenio OCDE, un documento adoptado por la misma conferencia negociadora del convenio pero que no forman parte de él, no son susceptibles de ratificación ni forman parte del convenio. Constituyen una suerte de guía interpretativa (SACERDOTI, G., «¿Sobornar o no sobornar?», en VV.AA., Las reglas del juego cambiaron: La lucha contra el soborno y la corrupción, OECD Publications, México, 2000, p. 41). 
sería deseable mejorar la redacción de la conducta típica, eliminando de una vez por todas la imprecisa expresión «corrompieren o intentaren corromper», que equipara la consumación del delito a la tentativa del mismo sin ninguna justificación, máxime cuando nuestro código penal ya castiga de manera general la tentativa. Si tal expresión ya fue suprimida en el ámbito del cohecho clásico en la reforma llevada a cabo en el año 2010, no hay razones para mantenerla en este precepto. El nuevo precepto podría utilizar los verbos habituales en los convenios internacionales y comenzar del siguiente modo: «El que, por sí o por persona interpuesta, ofrezca, prometa o conceda cualquier beneficio indebido, pecuniario o de otra clase...».

Por otra parte, debería el legislador plantearse una revisión acerca del tratamiento de los pagos de facilitación. Dado que, en ocasiones, muchos de ellos no tendrán si quiera potencial suficiente como para lesionar el bien jurídico de la competencia leal en el mercado internacional, las penas actualmente previstas podrían ser desproporcionadas.

Además, debería el legislador volver a incorporarse la expresión «[funcionario público] extranjero o de una organización internacional» pues los casos de soborno a funcionarios nacionales deberían llevarse por los tipos penales de cohecho clásico de los arts. 419 y siguientes.

Con todo, en último término no hay que olvidar que el nuevo art. 427 prevé el castigo del cohecho de cualquier funcionario público extranjero o internacional, no vinculado a la realización de actividades comerciales internacionales. Por tanto, llegados a este punto podemos preguntarnos si tiene sentido el mantenimiento del tipo específico de corrupción en las transacciones comerciales internacionales o si, por el contrario, podría eliminarse del código penal, evitando así problemas concursales; lo que llevaría a castigar toda conducta de corrupción transnacional conforme al nuevo art. 427. A mi juicio, el mantenimiento del delito de cohecho en las transacciones comerciales internacionales sólo tiene sentido si se defiende que tutela un bien jurídico diferente del tutelado por el art. 427, lo que llevaría a aplicar entre ambos un concurso de delitos, y no uno de leyes.

TITLE: Analysis of the crime of corruption incorporated in International business transactions by the Organic Law 1/2015 reforms, of March 30.

RESUMEN: La regulación del delito de corrupción en las transacciones comerciales en el Derecho español deriva del compromiso adquirido al ratificar diversos convenios internacionales en esta materia. Ante la falta de cumplimiento de algunos de estos compromisos, el legislador español ha previsto diversas modificaciones en la última ley de reforma del código penal. Este trabajo analiza esas modificaciones y ofrece propuestas de mejora. 
PALABRAS CLAVE: Comercio internacional, corrupción transnacional, funcionario público extranjero, funcionario de organización internacional, soborno transnacional.

ABSTRACT: The Spanish regulation on corruption in international business transactions derives from the commitment acquired by Spain after the ratification of several international conventions on this matter. Due to the fact that Spain has not complied with some of those commitments yet, the legislator has recently included some changes in the regulation of this type of offence. This paper analyses such changes and offers proposals for improvement.

KEY WORDS: International trade, transnational corruption, foreign public official, official of an international organisation, transnational bribery.

RECIBIDO: 07.05.2015 ACEPTADO: 22.05.2015 